\title{
World Journal of Comparison of inconclusive rates
Pediatric Surgery between suction rectal biopsy and open strip rectal biopsy in children of different age groups: a single-center retrospective study
}

To cite: Ng Liet Hing $\mathrm{Cl}$, Teng $\mathrm{R}$, Porrett L, et al. Comparison of inconclusive rates between suction rectal biopsy and open strip rectal biopsy in children of different age groups: a singlecenter retrospective study. World Jnl Ped Surgery 2020;3:e000080. doi:10.1136/wjps-2019-000080

Received 18 August 2019 Revised 29 December 2019 Accepted 30 December 2019

\section{Cedric lan Ng Liet Hing (D) , Roy Teng, Liesel Porrett, Richard Thompson}

\section{ABSTRACT}

Background Rectal biopsy for the diagnosis for Hirschsprung's disease (HD) can be performed in several ways. Suction rectal biopsy (SRB) is the most widely used method for neonates and younger infants while open strip biopsy (OSB) is reserved for older children. Current notions suggest that SRB should not be used in older infants due to perceived thicker fibrous tissue in their rectal walls leading to higher rates of inconclusive results. This study aims to compare the inconclusive rates of both methods in children of different age groups.

Methods A retrospective study were carried out with patients aged 13 years who underwent SRB or OSB during a 4-year period in a single center. Rectal biopsies were performed on patients with HD with previous endorectal pull-through surgeries excluded. Primary outcomes were rates of inconclusive results for SRB and OSB overall and when divided into different age groups.

Results 79 biopsies (57 SRB and 22 OSB) were included in the study. 12 biopsies (9 SRB and 3 OSB) were deemed inconclusive. There was no significant difference in the rate of inconclusive results between patients underwent SRB and OSB overall ( $15.8 \%$ vs $13.6 \%, p=1.000)$. The same results were obtained when patients were divided into under one year and over one year groups or other different age groups ( $30.0 \%$ vs $33.3 \%, p=1.000)$.

Conclusions Despite low biopsy numbers, our study suggests that SRB provides comparable rates of inconclusive results with OSB in children of all age groups.

\section{INTRODUCTION}

First described in 1887, Hirschsprung's disease (HD) is a condition characterized by the lack of ganglion cells normally found in the myenteric and submucosal plexuses of the colon. This aganglionic segment leads to a failure to relax resulting in a functional obstruction. It typically presents in neonates with features of complete bowel obstruction with delayed passage of meconium (greater than 48 hours of life), abdominal distension and vomiting. ${ }^{1}$ In addition to these clinical features, the NICE guidelines (2017)

\section{Summary Box}

What is already known about this subject?

- Hirschsprung's disease (HD) is a condition characterized by the lack of ganglion cells normally found in the myenteric and submucosal plexuses of the colon.

- The gold standard test for diagnosing HD is the rec tal biopsy.

- There is no recognized age cut-off for using suction rectal biopsy (SRB), but current notions suggest that it should not be used in older infants due to the increased fibrous tissue in their rectal wall leading to higher rates of inconclusive results.

\section{What are the new findings?}

- Our study found no significant difference in rates of inconclusive results between SRB and open strip biopsy (OSB).

- We also found no significant difference when patients were further divided into those aged under 1 year and those aged over 1 year.

- No significant differences were also found when further subdivided into different age groups.

How might it impact on clinical practice in the foreseeable future?

- These findings suggest that SRB is suitable for use in children of all ages and provides a theoretically less invasive alternative to full-thickness OSB.

also recommend that the presence of either chronic constipation, a family history of HD and/or faltering growth would necessitate further evaluation for HD. ${ }^{2}$

The gold-standard test for diagnosing HD is rectal biopsy, which requires histological evaluation of the submucosal plexus and myenteric plexus to delineate an absence of ganglion cells and hypertrophic nerve trunks. ${ }^{3}$ The first suction rectal biopsy (SRB) technique was introduced by Dobbins and Bill in 1961 and built on by Noblett in 1969 
including side apertures and a cylindrical knife. ${ }^{4-6}$ Our institution uses the newer rbi2 model which has been shown to be superior to the Noblett forceps at producing lower rates of inconclusive samples and being more cost-effective. $^{7}$

There is no recognized age cut-off for using SRB, but current notions suggest that it should not be used in older infants due to the increased fibrous tissue in their rectal wall leading to higher rates of inconclusive results. ${ }^{58}$ Previous studies have reported that SRB were suitable for use in patients less than 6 months old $^{89}$ while others found conclusive results in patients up to oneyear of age. ${ }^{11}$ One study even recommended the use of SRB in children above the age of five. ${ }^{12}$ Open strip biopsy (OSB) is currently the preferred method for older infants who require a general anesthetic to obtain rectal samples. Our institution, similarly, does not have a specific age limit for when each rectal biopsy technique should be used but has trend toward using SRB in the first instance due to its relative ease of use, cost-effectiveness and lower risk of complications compared with OSB.

This single-center study aims to compare the diagnostic accuracy of SRB with that of OSB in children of different age groups.

\section{METHODS}

\section{Design and data collection}

The study was a retrospective cohort study with all patients aged 13 years who underwent SRB or OSB by the pediatric surgical team over a 4-year period (from January 2015 to December 2018) at the Gold Coast University Hospital. All rectal biopsy modalities other than SRB or OSB were excluded. Rectal biopsies performed on patients with HD with prior endorectal pull-through surgeries to rule out a transitional zone pull through. Data were collected from a combination of sources including monthly pediatric surgical audits, and operative and pathology records. Patient demographics included age at time of procedure, gender, indication for biopsy and prior HD diagnosis.

\section{Classification of results}

The primary outcome measured was the diagnostic accuracy for each type of biopsy. This was based on various histological features notably amount of submucosa, presence of definite ganglion cells, calretinin response, nerve hypertrophy, presence of transitional anal epithelium and formal report by the pathologist. A biopsy result was deemed conclusive for diagnosing HD, if the sample contained the following: adequate amount of submucosa (determined by the pathologist), absence of definite ganglion cells and no transitional anal epithelium.

This result was then correlated with histology from the patient's future endorectal pull through. Presence of nerve hypertrophy (diameter $>0.4 \mathrm{~mm}$ ) was also evaluated as part of the result if mentioned.

A biopsy result was deemed conclusive for ruling out $\mathrm{HD}$, if the sample contained the following: definite presence of ganglion cells irrespective of the amount of submucosa present, absence of nerve hypertrophy or presence of normal nerve diameter $(<0.4 \mathrm{~mm})$ if mentioned as part of the result.

A biopsy result was deemed inconclusive, if the sample was superficial (with insufficient amount of submucosa determined by the pathologist) with no definite ganglion cells seen or if the sample was taken too distally and contained transitional anal epithelium.

\section{Biopsy techniques}

The rbi2 system was used to perform all SRBs with the company literature indicating use in patients of all ages from neonates to adults (rbi2: Suction Rectal Biopsy System. 2015. Electronic Brochure. Specialty Surgical Products, Inc: Aus Systems Pty Ltd). SRB was performed at the bedside without anesthesia in neonates and younger infants. Older infants, on the other hand, had SRB performed in the operating theater under general anesthetic. Typically, an SRB consisted of two or three specimens obtained along the posterior rectal wall at least $2 \mathrm{~cm}$ above the dentate line. As per the product instructions, the handpiece loaded with a disposable capsule was inserted into the rectum facing the posterior wall and suction was applied with a $5 \mathrm{~mL}$ syringe before the cutting blade was triggered.

All OSBs were performed in the operating theater under general anesthetic. A speculum was first inserted to provide direct vision of the posterior rectal wall. Using scissors, a single specimen was obtained in a submucosal plane at least $1-2 \mathrm{~cm}$ from the dentate line. The defect was then closed with dissolvable sutures for hemostasis and bowel wall repair.

\section{Histology}

Our pathology department follows a state-wide protocol for HD based on the Royal College of Pathologists recommendations by the state-wide committee of Specialist Pathologists.

All specimens were sent to pathology in formalin and sliced into 10 serial sections with a ribbon of sections on each slide. All sections except for serial 6 are stained with routine Haematoxylin and Eosin (H\&E) stain. Serial 7 was also stained with calretinin stain which was first introduced at our institution in 2016. Acetylcholinesterase stain, on the other hand, has not been validated for use by the National Association of Testing Authorities, Australia and is therefore not used by our pathology department. The pathologist reported on the macroscopic and microscopic features of the specimen looking specifically at the presence of ganglion cells, the amount of submucosa and the response to calretinin. Specimens with sufficient amounts of submucosa but no definite ganglion cells seen were typically reviewed by at least two pathologists to confirm the diagnosis of HD.

\section{Statistical analysis}

Continuous non-parametric data were presented as median (interquartile range, IQR) while categorical data 
were presented as count (percentage). Statistical tests include $\chi^{2}$ and Fisher's exact test for categorical data and Mann-Whitney $\mathrm{U}$ test for continuous non-parametric data.

All $\mathrm{p}$ values were two tailed with a significance level of $\alpha<0.05$. All data analyses were performed using SPSS V.25.

\section{RESULTS}

A total of 87 rectal biopsies were performed on 77 patients during the study period. One open biopsy performed during laparotomy and one forceps biopsy from two different patients were excluded. A further six rectal biopsies (three SRB and three OSB) from four different patients were excluded due to the history of endorectal pull-through surgeries for HD. A total of 79 biopsies (57 SRB and 22 OSB) from 71 patients were thus included in the study.

Sixty-two per cent $(49 / 79)$ of patients were male while $38 \%(30 / 79)$ of patients were female overall. The study population had a median age of 34 (IQR 6-64) months overall. Nine neonates (aged $<1$ month) were included with SRB performed on all of them. Eight neonates were referred due to clinical and radiological features consistent with large bowel obstruction while one was referred due to delayed passage of meconium. Moreover, $93.5 \%(58 / 62)$ of patients aged 1 month and above were referred for constipation while $6.5 \%(4 / 62)$ were referred for suspected bowel obstruction.

Eight patients were ultimately diagnosed with HD and underwent endorectal pull-through surgery while two patients were diagnosed with anorectal malformations and underwent anorectoplasty surgery. There were no complications associated with either biopsy technique.

Twelve biopsies (nine SRB and three OSB) from ten patients were deemed inconclusive. Table 1 shows a breakdown for each biopsy by number, type, age at time of procedure and final diagnosis.
Table 2 Breakdown of inconclusive results by histological reason and type of biopsy

\begin{tabular}{|c|c|c|c|c|}
\hline $\begin{array}{l}\text { Histological } \\
\text { reason }\end{array}$ & $\begin{array}{l}\text { Total } \\
(n=12)\end{array}$ & $\begin{array}{l}\text { Suction } \\
\text { rectal } \\
\text { biopsy } \\
(n=9)\end{array}$ & $\begin{array}{l}\text { Open } \\
\text { strip } \\
\text { biopsy } \\
(n=3)\end{array}$ & $P$ value \\
\hline Superficial, n (\%) & $7(58.3)$ & 7 (100.0) & $0(0.0)$ & $<0.001$ \\
\hline Distal†, n (\%) & $4(33.3)$ & $1(25.0)$ & $3(75.0)$ & 0.625 \\
\hline $\begin{array}{l}\text { Lymphoid } \\
\text { follicles } \neq, n(\%)\end{array}$ & $1(8.3)$ & $1(100.0)$ & $0(0.0)$ & 1.000 \\
\hline
\end{tabular}

Calretinin stain was performed on $60.8 \%$ (48/79) of biopsies while nerve diameter was only reported in $46.8 \%$ (37/79) of biopsies overall.

*Superficial=containing limited or no submucosa for evaluation. †Distal=containing anorectal junction mucosa not suitable for evaluation.

łLymphoid follicles=presence of lymphoid follicles preventing accurate evaluation.

One patient had a conclusive SRB performed at 3 years old with the sample reporting minimal submucosa for assessment but with three definite ganglions identified, effectively ruling out HD. The patient continued to suffer from chronic constipation and subsequently underwent an MRI which raised the possibility of a transition zone. $\mathrm{He}$ had a further conclusive OSB at 4 years old which again ruled out HD.

A further breakdown of all the histological reasons why biopsies were deemed inconclusive is given in table 2 .

Table 3 shows no significant differences in gender distribution between the SRB and OSB groups $(p=0.121)$. Patients in the OSB group had a higher median age in months compared with the SRB group, but this was not statistically significant $(p=0.096)$. One hundred per cent of neonates included in the study had SRB performed. Notably, there was no significant difference in the rate of inconclusive results between SRB and OSB overall ( $15.8 \%$ vs $13.6 \%, \mathrm{p}=1.000)$.

\begin{tabular}{|c|c|c|c|c|c|c|c|}
\hline \multirow[b]{2}{*}{ Patient } & \multicolumn{2}{|c|}{ First inconclusive $\mathrm{Bx}$} & \multicolumn{2}{|c|}{ Second inconclusive $\mathrm{Bx}$} & \multicolumn{2}{|c|}{ Conclusive Bx } & \multirow[b]{2}{*}{ HD diagnosis } \\
\hline & Type & Age & Type & Age & Type & Age & \\
\hline 1 & SRB & Neonate & - & - & SRB & $1 \mathrm{mo}$ & Negative \\
\hline 2 & SRB & Neonate & - & - & OSB & $11 \mathrm{mo}$ & Positive \\
\hline 3 & OSB & $3 y$ & - & - & OSB & $4 y$ & Negative \\
\hline 4 & SRB & $2 y$ & SRB & $2 y$ & OSB & $2 y$ & Positive \\
\hline 5 & SRB & $6 \mathrm{mo}$ & OSB & 7 mon & OSB & $9 \mathrm{mo}$ & Negative \\
\hline 6 & SRB & 7 y & - & - & Lap Bx & $7 y$ & Positive \\
\hline 7 & SRB & Neonate & - & - & \multicolumn{2}{|c|}{ Improved clinically } & Negative \\
\hline 8 & SRB & $1 \mathrm{mo}$ & - & - & \multicolumn{2}{|c|}{ Improved clinically } & Negative \\
\hline 9 & OSB & $4 y$ & - & - & \multicolumn{2}{|c|}{ Improved clinically } & Negative \\
\hline 10 & SRB & $6 \mathrm{mo}$ & - & - & \multicolumn{2}{|c|}{ Improved clinically } & Negative \\
\hline
\end{tabular}

Bx, biopsy; HD, Hirschsprung's disease; OSB, open strip biopsy; SRB, suction rectal biopsy. 
Table 3 Patient characteristics and rates of inconclusive results

\begin{tabular}{|c|c|c|c|c|}
\hline Variables & $\begin{array}{l}\text { Total } \\
(n=79)\end{array}$ & $\begin{array}{l}\text { Suction rectal biopsy } \\
(\mathrm{n}=57)\end{array}$ & $\begin{array}{l}\text { Open strip biopsy } \\
(n=22)\end{array}$ & $P$ value \\
\hline Gender, n (\%) & & & & 0.121 \\
\hline Male & $49(62.0)$ & $32(56.1)$ & $17(77.3)$ & \\
\hline Female & $30(38.0)$ & 25 (43.9) & $5(22.7)$ & \\
\hline \multicolumn{5}{|l|}{ Age, n (\%) } \\
\hline In months & $34(6-64)$ & $30(2-67)$ & $43(25-61)$ & 0.096 \\
\hline In years & $2(0-5)$ & $2(0-5)$ & $3(2-5)$ & 0.161 \\
\hline Neonates & $9(11.4)$ & $9(100.0)$ & $0(0.0)$ & $<0.001$ \\
\hline Thickness, median (range) & $3.0(2.0-3.0)$ & $2.0(2.0-3.0)$ & $3.0(3.0-5.5)$ & $<0.001$ \\
\hline \multicolumn{5}{|l|}{ Results, n (\%) conclusive } \\
\hline $\begin{array}{l}\text { HD diagnosed } \\
\text { (true positive) }\end{array}$ & $8(10.1)$ & $6(10.5)$ & $2(9.1)$ & \\
\hline HD excluded (true negative) & $59(74.7)$ & $42(73.7)$ & 17 (77.3) & \\
\hline Total & $67(84.8)$ & $48(84.2)$ & $19(86.4)$ & 1.000 \\
\hline Inconclusive (false positive) & $12(15.2)$ & $9(15.8)$ & $3(13.6)$ & \\
\hline
\end{tabular}

HD, Hirschsprung's disease.

Table 4 shows no significant difference in the rate of inconclusive results between SRB and OSB when patients were further divided into those aged under 1 year $(30 \%$ vs $33.3 \%, \mathrm{p}=1.000)$ and those aged 1 year and above $(8.1 \%$ vs $10.5 \% \mathrm{p}=1.000$ ).

Similarly, table 5 shows no significant difference in the rate of inconclusive results between SRB and OSB in patients aged $1-2$ years $(16.7 \%$ vs $0 \%, p=1.000)$, aged $3-4$ years $(0 \%$ vs $22.2 \%, \mathrm{p}=0.471)$ and those aged 5 years and above $(6.3 \%$ vs $0 \%, \mathrm{p}=1.000)$.

\section{DISCUSSION}

Our study set out to find whether SRB produced similar rates of inconclusive results as OSB in patients with different age groups. Earlier studies suggested that SRB should only be performed in children younger than 6 months of age. ${ }^{89}$ This age limit was subsequently increased with children up to 1 year of age deemed suitable for SRB. ${ }^{10}{ }^{11}$ Croffie et al found that SRBs, when performed

\begin{tabular}{|c|c|c|c|}
\hline & $\begin{array}{l}\text { Suction } \\
\text { rectal } \\
\text { biopsy }\end{array}$ & $\begin{array}{l}\text { Open strip } \\
\text { biopsy }\end{array}$ & $P$ value \\
\hline \multicolumn{4}{|l|}{$<1$ year, $\mathrm{n}(\%)$} \\
\hline Total & 20 & 3 & 1.000 \\
\hline Conclusive & $14(70.0)$ & 2 (66.7) & \\
\hline Inconclusive & $6(30.0)$ & 1 (33.3) & \\
\hline \multicolumn{4}{|l|}{$\geq 1$ year, n (\%) } \\
\hline Total & 37 & 19 & 1.000 \\
\hline Conclusive & 34 (91.9) & $17(89.5)$ & \\
\hline Inconclusive & $3(8.1)$ & $2(10.5)$ & \\
\hline
\end{tabular}

in children older than 3 years, were less likely to provide adequate submucosa to identify ganglion cells compared with uterine grasper forceps. ${ }^{5}$ Even more recently, Brady et al found that SRB yielded accurate results even in children older than 5 years. ${ }^{12}$

Overall, our study found no significant difference in rates of inconclusive results between SRB and OSB ( $15.8 \%$ for SRB vs $13.6 \%$ for OSB, $p=1.000$ ). We also found no significant difference when patients were further divided into those aged under 1 year and those aged over 1 year or when subdivided into different age groups. This finding suggests that SRB provides comparable rates of inconclusive results with OSB in patients of all age groups as recently demonstrated in a study by Muise et al. ${ }^{13}$ They, however, found that SRB produced

Table 5 Rates of conclusive and inconclusive (\%) results in different age brackets

\begin{tabular}{llll}
\hline & $\begin{array}{l}\text { Suction rectal } \\
\text { biopsy }\end{array}$ & $\begin{array}{l}\text { Open strip } \\
\text { biopsy }\end{array}$ & P value \\
\hline 1-2 years, $\mathrm{n}(\%)$ & & & \\
\hline Total & 12 & 5 & 1.000 \\
Conclusive & $10(83.3)$ & $5(100.0)$ & \\
$\quad$ Inconclusive & $2(16.7)$ & $0(0.0)$ & \\
3-4 years, $\mathrm{n}(\%)$ & & & \\
Total & 9 & 9 & \\
Conclusive & $9(100.0)$ & $7(77.8)$ & \\
Inconclusive & $0(0.0)$ & $2(22.2)$ & \\
$\geq 5$ years, $\mathrm{n}(\%)$ & & & \\
Total & 16 & 5 & \\
Conclusive & $15(93.8)$ & $5(100.0)$ & \\
Inconclusive & $1(6.3)$ & $0(0.0)$ & \\
\hline
\end{tabular}


equivalent submucosa to OSB which differed from our own study's finding that SRB specimens were less thick than OSB specimens ( $2 \mathrm{~mm}$ vs $3 \mathrm{~mm}, \mathrm{p}<0.001$ ) leading to a higher proportion of inconclusive results due to being superficial with limit to no submucosa present $(77.8 \%)$. Previously established consensus for any rectal biopsy specimen included a depth of $1 \mathrm{~mm}$ with equal mucosa and submucosa, ${ }^{14-16}$ and our study's median thickness of $2 \mathrm{~mm}$ for SRB was still within range.

Interestingly, a higher proportion of patients with an inconclusive and superficial SRB were aged less than 1 year compared with more than 1 year $(57.1 \%$ vs $42.9 \%$, $\mathrm{p}=1.000$ ). Despite the small sample size, this finding contradicts the popular belief that SRB yields more superficial and inconclusive results in older infants due to their thicker and more fibrous rectal wall.

Our study's operative records reported that OSB was taken at least $1-2 \mathrm{~cm}$ from the estimated dentate line. However, all inconclusive results for OSB resulted from specimens being obtained too distal in the rectum with the presence of anorectal junction mucosa. This was due to inaccurate estimation of the dentate line by the operator resulting in the specimen being obtained closer than estimated. SRB, on the other hand, typically involved at least two or three samples, each $1 \mathrm{~cm}$ apart, starting $2 \mathrm{~cm}$ from the dentate line. Moreover, the rbi2 disposable capsule contained $1 \mathrm{~cm}$ markings which made it easier to gauge the distance required. This greatly reduceed the likelihood for samples obtained too distally.

The retrospective nature of our study makes it susceptible to various inherent biases which impact on the accuracy of the data. The relatively small population size also restricts its ability to demonstrate statistical significance. Certain variables which could potentially alter the findings of the study were either inconsistently reported or not reported at all. The distance from the dentate line where each SRB was obtained was inconsistently reported. This was also true to a lesser degree for OSB.

From a histological point of view, inconsistently reported features such as calretinin stain (which was not introduced at our institution until 2016 and performed in only $60.8 \%$ of biopsies) and nerve diameter (reported in only $46.8 \%$ of biopsies) have potential to alter our primary outcome if recorded accurately. Furthermore, the submucosa is qualitatively assessed by the pathologist and whether the submucosal tissue is deemed adequate may vary from one pathologist to another.

Despite the above limitations, our study supports newer literature advocating for use of SRB in children of all ages. Its relative ease of use, cost-effectiveness and lower risk for complications make it an ideal technique for obtaining rectal biopsies. Future research would ideally consist of multicenter prospective cohort studies looking at replicating or further emphasizing the current study's findings on a larger scale. Standardized recording of specific operative details (such as distance from dentate line and operator level) and histological features (such as calretinin stain, nerve diameter, quantity of submucosa) also have potential to affect the outcome of each biopsy sample. A cost-analysis study would help quantify how effective SRB is compared with other biopsy techniques while a survey distributed to pediatric surgical trainees could look at how easy the rbi2 biopsy gun is to use.

Acknowledgements The authors would like to thank the Gold Coast Health Service pathology department and Professor Alfred Lam (pathologist) for their succinct pathology reports and for their help with explaining the staining process.

Contributors RoT and LP devised the project, the main conceptual ideas and proof outline. CINLH and RT collected the data, performed the data analysis and wrote the draft. RiT supervised and directed the project.

Funding The authors have not declared a specific grant for this research from any funding agency in the public, commercial or not-for-profit sectors.

Competing interests None declared.

Patient consent for publication Not required.

Ethics approval The project was acknowledged by the Gold Coast Hospital and Health Service Human Research Ethics Committee (HREC) as a low and negligible risk project undertaken in an ethical manner. LNR/2019/QGC/54346.

Provenance and peer review Not commissioned; externally peer reviewed.

Data availability statement Data are available on reasonable request.

Open access This is an open access article distributed in accordance with the Creative Commons Attribution Non Commercial (CC BY-NC 4.0) license, which permits others to distribute, remix, adapt, build upon this work non-commercially, and license their derivative works on different terms, provided the original work is properly cited, appropriate credit is given, any changes made indicated, and the use is non-commercial. See: http://creativecommons.org/licenses/by-nc/4.0/.

ORCID iD

Cedric lan Ng Liet Hing http://orcid.org/0000-0003-1441-9526

\section{REFERENCES}

1 Hutson JM, O'Brien M, Beasley SW, et al. Jones' clinical paediatric surgery. 6th edn. Malden, MA: Blackwell Publishing, 2008.

2 NICE. Constipation in children and young people: diagnosis and management, 2017.

3 Muise ED, Cowles RA. Rectal biopsy for Hirschsprung's disease: a review of techniques, pathology, and complications. World J Pediatr 2016;12:135-41.

4 Dobbins WO, Bill AH. Diagnosis of Hirschsprung's disease excluded by rectal suction biopsy. N Engl J Med 1965;272:990-3.

5 Croffie JM, Davis MM, Faught PR, et al. At what age is a suction rectal biopsy less likely to provide adequate tissue for identification of ganglion cells? J Pediatr Gastroenterol Nutr 2007;44:198-202.

6 Noblett HR. A rectal suction biopsy tube for use in the diagnosis of Hirschsprung's disease. J Pediatr Surg 1969;4:406-9.

7 Hall NJ, Kufeji D, Keshtgar A. Out with the old and in with the new: a comparison of rectal suction biopsies with traditional and modern biopsy forceps. J Pediatr Surg 2009;44:395-8.

8 Alizai NK, Batcup G, Dixon MF, et al. Rectal biopsy for Hirschsprung's disease: what is the optimum method? Pediatr Surg Int 1998;13:121-4.

9 Allen AR, Putnam AR, Presson AP, et al. Accuracy of suction rectal biopsy for diagnosis of Hirschsprung's disease in neonates. Eur $J$ Pediatr Surg 2019;29:425-30.

10 Khan AR, Vujanic GM, Huddart S. The constipated child: how likely is Hirschsprung's disease? Pediatr Surg Int 2003;19:439-42.

11 Rahman Z, Hannan J, Islam S. Hirschsprung's disease: role of rectal suction biopsy-data on 216 specimens. J Indian Assoc Pediatr Surg 2010;15:56-8.

12 Brady A-C, Saito JM, Lukas K, et al. Suction rectal biopsy yields adequate tissue in children. J Pediatr Surg 2016;51:966-9.

13 Muise ED, Hardee S, Morotti RA, et al. A comparison of suction and full-thickness rectal biopsy in children. J Surg Res 2016;201:149-55.

14 Qualman SJ, Jaffe R, Bove KE, et al. Diagnosis of Hirschsprung disease using the rectal biopsy: multi-institutional survey. Pediatr Dev Pathol 1999;2:588-96.

15 Campbell PE, Noblett HR. Experience with rectal suction biopsy in the diagnosis of Hirschsprung's disease. J Pediatr Surg $1969 ; 4: 410-5$. 
